\title{
THE SEVERITY OF SMOULDERING PEAT FIRES AND DAMAGE TO THE FOREST SOIL
}

\author{
Guillermo Rein ${ }^{\mathrm{I}}$, Natalie Cleaver, Clare Ashton, \\ Paolo Pironi and José L. Torero \\ BRE Centre for Fire Safety Engineering \\ University of Edinburgh, UK
}

\begin{abstract}
Smouldering wildfires propagate slowly through surface and subsurface organic layers of the forest ground and severely affect the soil, producing physical, chemical and biological changes. These effects are caused by the prolonged heating and the large loss of soil mass but poorly documented in the literature. A series of smouldering experiments with boreal peat have been conducted under laboratory conditions to quantify these effects using small-scale samples. Peat samples of 100 $\mathrm{mm}$ by $100 \mathrm{~mm}$ in cross section and $50 \mathrm{~mm}$ in depth of different moisture were exposed to an external ignition source. Thermocouples placed throughout the sample bed measured the temperature evolution and tracked the peat ignition, intensity and spread of the smouldering front. The results show that moisture content controls peat ignition and that moisture contents below $125 \pm 10 \%$ (in dry base) are required. The severity of the smouldering peat on the soil has been quantified in terms of temperature vs. residence-time curves and mass loss. The measurements show temperatures in excess of $300{ }^{\circ} \mathrm{C}$ for residence times of $1 \mathrm{~h}$ leading to sterilization of the soil and mass loss in burnt layers above $90 \%$.
\end{abstract}

Keywords: wildfire; biomass; thermal damage; mass loss; moisture.

\section{INTRODUCTION}

When a layer of organic soil ignites, it burns steadily without flame and propagates slowly into the soil. Smouldering of the forest ground does not have the visual impact of the flaming front but constitutes an important factor in wildfires and the subsequent damage to the forest. Large smouldering fires are rare events at the local scale but occur regularly at a global scale. Once ignited, they are particularly difficult to extinguish despite extensive rains or firefighting attempts and can linger for long periods of time (weeks and up to years (Page et al. 2002; Svensen et al. 2003)), and spread over very extensive areas of forest and deep into the soil. By propagating below the surface, smouldering fires offer the means for flaming combustion to re-establish during wildfires in unexpected locations (e.g. across a fire break) and at unexpected times (e.g. long after burn out of the flame front). These fires represent a large contributor to biomass consumption and a significant source of combustion emissions to the atmosphere (Page et al. 2002; Breschti et al. 2003; Rein et al. 2008).

The effects of smouldering fires on the landscape can range from the small scale (pockets of burning in superficial layers or the root of a single tree), to the large scale (burning of a hill-top or the destruction of the root network of a complete forest stand). In general, smouldering fires have a severe impact on the local soil system, because the burning fuel is the organic portion of the soil itself. The prolonged heating from the slowly propagating fire can kill roots, seeds and plant stems and the affected layers of soil sustain large losses of biomass. This coupled with expositing of underlying layers increases the likelihood of long term damage and erosion.

Of all the natural organic soils, fire in peatlands is the most common and has been reported in tropical, temperate and boreal forests, e.g. South-East Asia (Page et al. 2002, Usup et al. 2004), Northern America (Frandsen, 1987; Frandsen, 1997; Santa Barbara County, 2000), Siberia (Artsybashev et al. 1983), the British Isles (Maltby et al. 1990; Bragg and Tallis, 2001), Finland (Pitkänen et al. 1999), Falkland Isles (Poncet, 2004), Southern Africa (Gumbricht et al. 2002) and others. Peat is partially decayed vegetation matter which has accumulated and decomposed in wetlands. It can have very high moisture contents (several times the weight of the organic content), and forms layers of depths ranging from a few centimeters to dozens of meters. Of all the peat lands in the world, about $80 \%$ are situated in northern temperate regions, $15-20 \%$ in tropical or subtropical regions and only a few are in southern temperate regions. Peatlands cover over 4 million $\mathrm{km}^{2}$ (3\% of the Earth's land surface) and are important ecosystems for a wide range of wildlife habitats supporting

\footnotetext{
${ }^{1}$ Corresponding Author: G.Rein@ed.ac.uk
} 
biological diversity, hydrological integrity and carbon storage. These ecosystems hold one third of the world's soil carbon and $10 \%$ of global freshwater resources. Their total carbon pool exceeds that of the world's forests and is comparable to that of the atmosphere (Joosten and Clark, 2002).

\section{SMOULDERING FIRES}

Smouldering is the flameless form of combustion of a solid fuel (Palmer, 1957; Drysdale, 1998). The fundamental difference between smouldering and flaming combustion is that, in the former, the oxidation reaction and the heat release occur on the surface of the solid and, in the latter, these occur in the gas phase above the fuel. Figure 1 shows a snapshot of the two burning regimes in forest floor biomass.

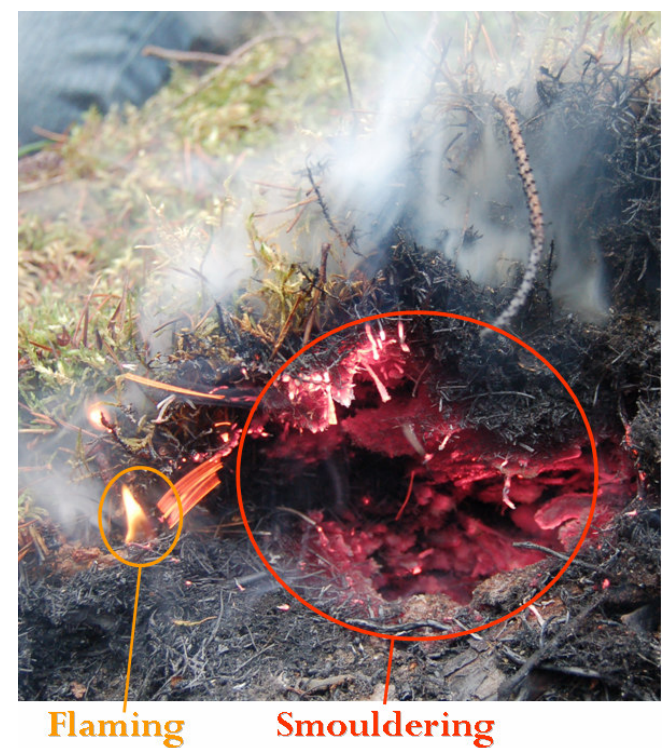

Figure I: Snapshot showing the two regimes of biomass burning during a wildfire; flaming of the grass and smouldering of the organic soil. For scale reference, the flame is about to $\mathrm{mm}$ tall.

The characteristic temperature, spread rate and heat release rate during smouldering are low compared to those in the flaming combustion. Typical values for smouldering of biomass are $500-700{ }^{\circ} \mathrm{C}$ for the peak temperature and ${ }_{1-50} \mathrm{~mm} \cdot \mathrm{h}^{-1}$ for the spread rate; whereas typical values for flaming are around $1500{ }^{\circ} \mathrm{C}$ and $1000 \mathrm{~mm} \cdot \mathrm{h}^{-1}$ respectively (Drysdale, 1998). The hazards associated with smouldering arise because it can be initiated by weak sources of heat; yields a high conversion of biomass to volatile organic compounds, carbon monoxide and polyaromatic hydrocarbons (Bertschi et al. 2003); is difficult to detect and extinguish; and it can abruptly transition to flaming combustion.

Biomass fuels prone to smouldering include stumps, snags, downed logs, large branches, roots, duff, peat, coal and other organic soils. These fuels generally consist of an aggregate medium formed by particulates, grains, fibers or a porous matrix. The aggregate contains the organic fraction that burns during the fire. These fuels are characterized by having a significantly greater characteristic thermal time than fine fuels but allow oxygen transport to the surface; characteristics that lead to the slow but persistent burning typical of smouldering combustion.

Figure 2 shows a photograph of a sample of peat where a smouldering front has been initiated and is propagating laterally. Superimposed on the photograph is a schematic of the smouldering front structure that can be observed with the naked eye. Generally speaking, there are three visually discernable regions propagating in a biomass smouldering front. These are:

- Preheating region: the undisturbed peat is gradually heated as the front approaches a given location. The solid is heated to temperatures between $80^{\circ} \mathrm{C}$ and $100{ }^{\circ} \mathrm{C}$ at which drying takes place, absorbing heat to convert the liquid water into vapour.

- Burning region: this front is where the pyrolysis and oxidation reactions take place and net heat is released. Pyrolysis reaction absorbs heat and converts the peat into volatile gases and char. In peat, pyrolysis takes place approximately at temperatures between $250-300{ }^{\circ} \mathrm{C}$ (Usup et al. 2004). Pyrolysis is stronger at deeper layers of soil where oxygen transport is reduced and oxidation rate is lower. The oxidation reaction consume organic matter and oxygen from the 
air releasing heat. In peat, this occurs approximately at temperatures between $300-350{ }^{\circ} \mathrm{C}$ (Usup et al. 2004) and results in peak temperature around $600{ }^{\circ} \mathrm{C}$. The net heat released by the burning front drives the propagation through the biomass.

- Char and ash region: this is where the smouldering has ceased and the remaining matter cools down to ambient temperature. The ash is the mineral content present in the original peat that is left after complete consumption of the soil and the char is the result of partial burning of the organic fraction.

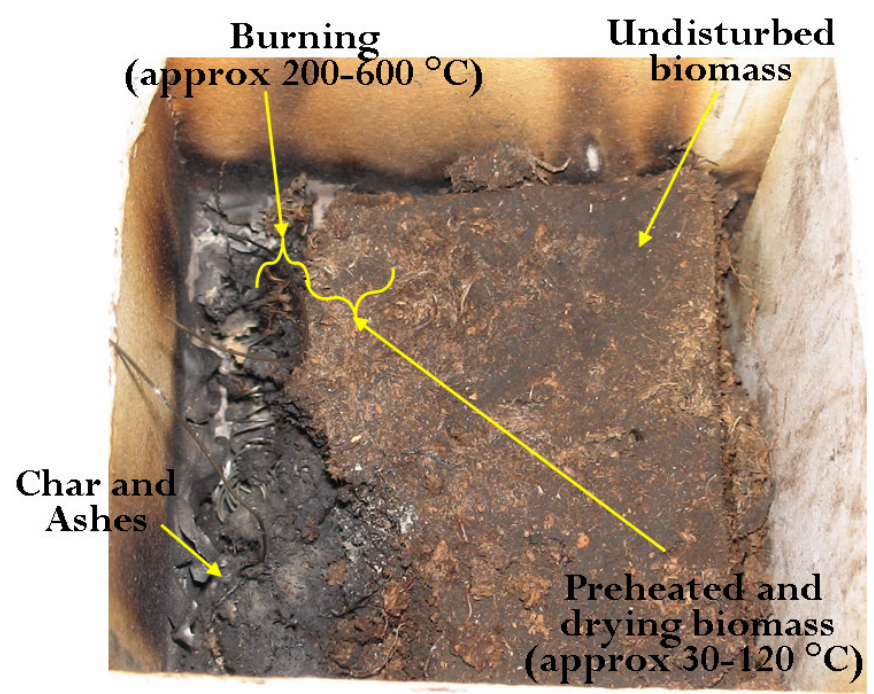

Figure 2: Photograph of a burning peat sample. Superimposed is a schematic of the smouldering front structure. For scale reference, the sample is $100 \mathrm{x}$ 100 $\mathrm{mm}$ in size.

The primary controlling mechanisms of smouldering fires are the net fuel load i.e. organic content (Frandsen, 1987), the oxygen diffusion and availability which is dictated by the distance to the free surface and permeability of the medium to air (Palmer, 1957) and the heat losses predominantly by evaporation and heat lost from the reaction zone by conduction, convection and in a lesser quantity radiation (Frandsen, 1987). The mineral and the moisture contents reduce the fuel load per total mass and also result in a lower net heat release value because the evaporation of water and the heating up of the mineral mass absorb heat. There is a critical value for water and mineral contents above which biomass smouldering cannot propagate (Frandsen, 1987). This implies that the natural spatial distribution (vertical and horizontal) of moisture and mineral content in the soil has a large influence on the ignitability of smouldering fires and extent of the affected areas. The role of moisture content in smouldering wildfires has been studied by Hille and Stephens (2005) and Miyanishi and Johnson (2002). Both papers found a strong correlation between higher duff consumption and distance from the base of the trees. They proposed that this is due to effect of crown cover reducing the rainfall on the duff beneath, resulting in drier soils close to the tree bases.

\section{EFFECTS ON THE SOIL}

The changes to the soil produced by smouldering fires in organic soils are driven by two factor: the high temperatures reached and the large loss of soil mass.

The most important physical change produced by smouldering fires is that affecting the stability of the ground. The removal of soil layers at the surface leads to enhanced erosion and the destruction of deeper layers can lead to structural collapse. Over-hangs, holes in the ground and pan-shape voids around tree bases are commonly produced during smouldering fires and can lead to local subsidence of the soil and damage to roots, threatening tree stability and disturbing hydrology dynamics.

Heating of the soil by wildfire produces changes of chemical nature including loss of carbon, nitrogen and organic phosphorus or the gain of inorganic phosphorus and calcium concentrations (Smith et al. 2001; Certini, 2005). Changes of biological nature produced by heating the soil include the modification of nutrient availability, perturbation of microbial dynamics, growth of invasive plant species and irreversible damage to local species (Smith et al. 2001; Certini, 2005).

The thermal severity can be described by the temperatures reached on the soil and the residence time of this heating (Hartford and Frandsen, 1992; Perez and Moreno, 1998; Certini, 2005). The thermal severity on the soil is significantly larger and reaches deeper layers during smouldering fires than flaming fires (Hartford and Frandsen, 1992; Smith et al. 
2001). In general terms, flaming fires produce very high temperatures away from the ground for short periods of time (i.e. in the order of a few minutes). This results in minimal heating of the soil below depth of a few centimeters, reaching peak temperatures of 300 to $500{ }^{\circ} \mathrm{C}$ at very superficial layers and below $80{ }^{\circ} \mathrm{C}$ at depths around $40 \mathrm{~mm}$ (Hartford and Frandsen. 1992). Smouldering fires, however, lead to enhanced heat transfer to the soil for much longer durations (i.e. in the order of one hour). This results in peak temperatures in the range of 400 to $600{ }^{\circ} \mathrm{C}$ and a smouldering front that can span from superficial to deep layers. This means that the soil is exposed to conditions that are lethal to biological systems. The severity of smouldering fires has been identified as an important factor in tree mortality (Hartford and Frandsen, 1992), as important as the damage to tree crowns resulting from flaming fires (Stephens and Finney, 2002).

A recent case of a smouldering fire causing major damage to the landscape and the ecosystem is the wildfire that occurred in a 40 year old, 15 ha plantation of lodgepole pines in Rothiemurchus near Aviemore, Scotland, during July 2006 (Legg and Davies, 2006). The flaming fire was extinguished by the fire service within three days, but the peat underneath the forest continued to smoulder for more than forty days despite the occasional rains. To stop the smouldering spread, the fire service dug a fire-break trench $5 \mathrm{~m}$ wide and 0.5 to $2 \mathrm{~m}$ deep at the perimeter of the affected layers to remove the peat and expose the mineral soil. Figure 3 shows photographs of adjacent forest stands after the fire. While the flaming fire scorched the trees up to $1 \mathrm{~m}$ from the floor and consumed some of the grass, the smouldering fire burned the peat up to depths of 0.5-1 m removing large quantities of the soil. The root systems and tree bases were by far the most affected areas by smouldering. Many smouldering pan-shape voids were seen around forest stands and single trees. These were formed by the removal of large portions of soil in approximately circular areas 0.5 to $3 \mathrm{~m}$ around the tree bases and exposing the mineral soil layers beneath. A dependence of peat consumption patterns on the distance from the base of the trees was also observed in several areas of the forest (not shown in Figure 3), in a similar pattern to that noted by Hille and Stephens (2005) and Miyanishi and Johnson (2002). Near the bases of trees, where crown cover reduces the rainfall and roots take up water, there is a much higher degree of peat consumption and the fire spread by following the roots. This suggests that the fire pattern in Rothiemurchus was largely influenced by the moisture distribution of the peat. The effect of plough lines is most probably of importance too in explaining spread patterns but more information is required to draw reasonable conclusions.

4 .

\section{PEAT SMOULDERING EXPERIMENTS}

The only systematic experiments of peat ignition are those by Frandsen (1987) and Frandsen (1997). These report that peat moss can ignite if the moisture content is below $110 \%^{2}$ in dry base. An experimental apparatus similar to that of Frandsen (1987) has been built for this work to investigate the relationship between the moisture content and smouldering behaviour. Modifications have been made to measure spread and temperature evolution and distribution. This apparatus provides a simple procedure to capture the essentials of peat ignition and propagation. It allows estimation of the moisture content below which ignition is highly probable (the critical moisture) and characterization of the thermal severity of smouldering.

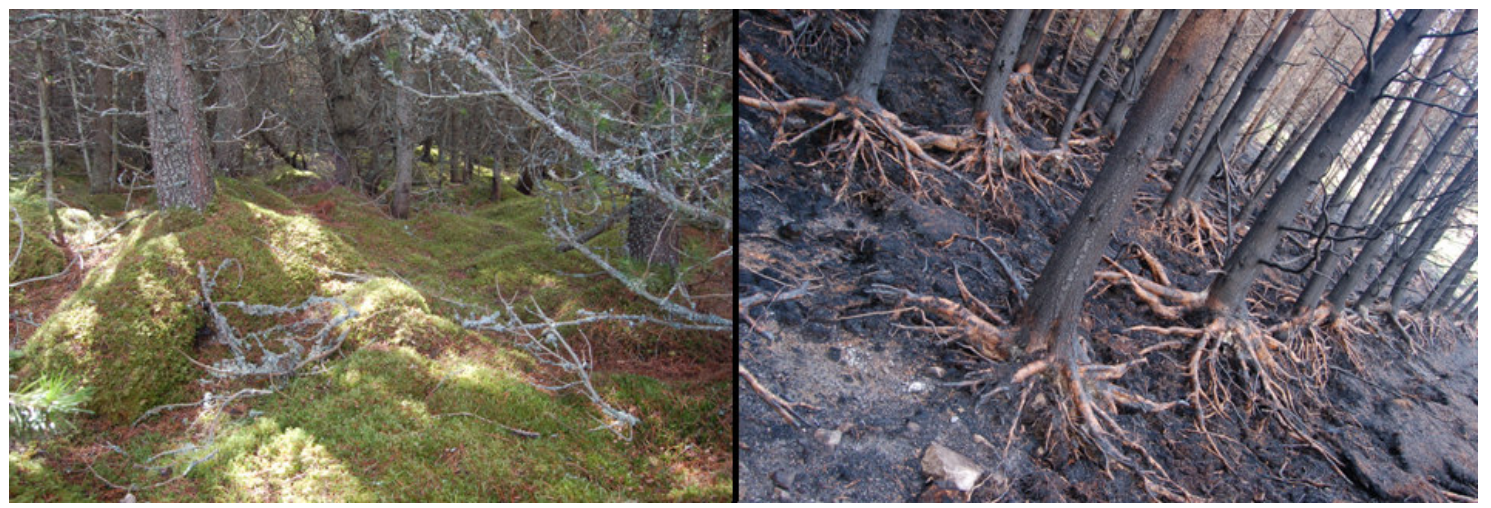

Figure 3: Photographs of adjacent forest stands from the July 2006 Rothiemurchus peat fire in Scotland.

Left: Stand not affected by the fire showing the trees and the peat layer. Right: Stand of trees trunks charred by the flames and the soil destroyed by smouldering fire.

Boreal peat was collected from a site south of Edinburgh, Scotland. The samples were cut from several blocks of old, moderately decomposed herbaceous peat. The measured bulk density of the dry mass was $430 \mathrm{~kg} \cdot \mathrm{m}^{-3}$ and the mineral content was $8 \pm_{2} \%$ in dry base (measured as the mass fraction left after complete combustion with a flame torch). The

${ }^{2}$ All moistures values in this paper are expressed as \% of the dry mass, which results in most values being greater than $100 \%$. 
moisture content of the peat samples was varied between $85 \%$ and $160 \%$ by placing samples of approximate initial moisture $400 \%$ in an oven at $80^{\circ} \mathrm{C}$ for varying periods of time. The moisture within the sample was allowed to equilibrate by placing it during 3 days at ambient temperature and wrapped in plastic.

Figure 4 shows the experimental set up and the progression of the smouldering front during one experiment. The tests were conducted in a small box $100 \times 100 \times 100 \mathrm{~mm}$ made of insulating board and open at the top. Samples are of dimensions $100 \times 100 \mathrm{~mm}$ across and $50 \mathrm{~mm}$ in depth. Ignition is attempted using an electrically heated coil running along one side of the sample. The coil is a spiral $10 \mathrm{~mm}$ diameter and $95 \mathrm{~mm}$ long. It was buried in the peat at a depth of $30 \mathrm{~mm}$ and placed next to the left wall of the experimental apparatus (see Fig. 4). The ignition protocol consisted of supplying the coil with a power of $100 \mathrm{~W}$ during $30 \mathrm{~min}$. In order to reduce the sensitivity of the results in this study to the details of the ignition protocol, a vigorous ignition roughly equivalent to the heating from a flaming stump is chosen. The criterion for ignition rating is based on the propagation of the smouldering front away from the igniter and through the full sample. This ignition protocol and criterion are used because the measured critical moisture in small-scale samples could, to some extent, be sensitive to the ignition protocol. This protocol and criterion provide the upper bound of the critical moisture and is valid for conservative ignition ratings.

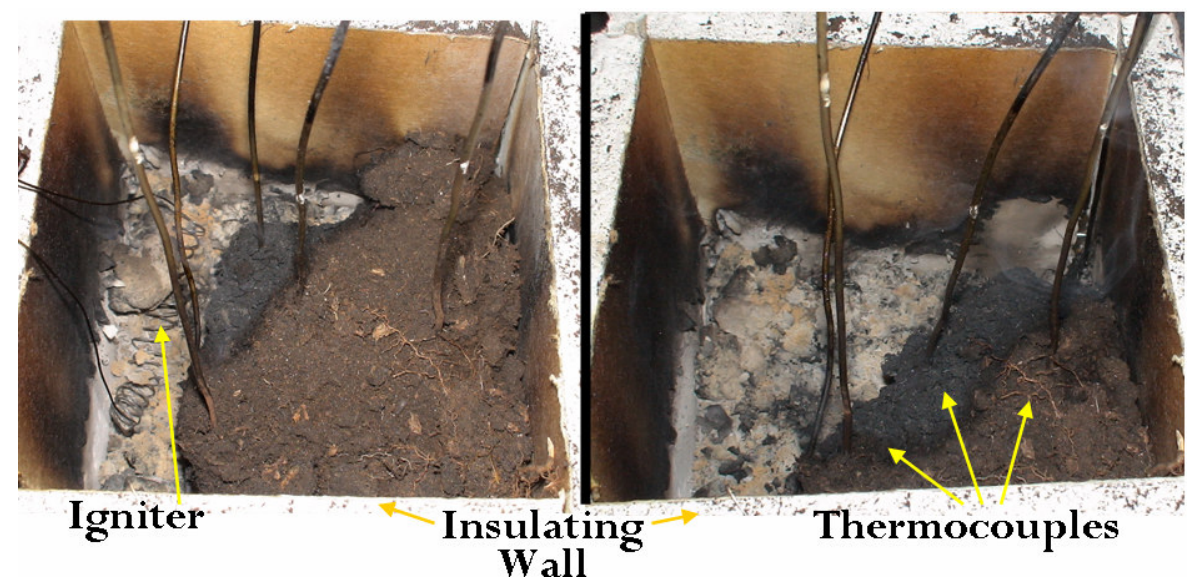

Figure 4. Two snapshots during one of the experiments that reached strong ignition of the peat (moisture content 100\%) showing the progression of the smouldering front. Location of the igniter and the thermocouples is indicated. Time elapsed between the left and the right photographs is about $\mathrm{I} h$. Note that propagation is not uniform across the box.

Five thermocouples are placed within the sample to a depth of $40 \mathrm{~mm}$. One thermocouple is placed near the igniter coil, less than $10 \mathrm{~mm}$ from the left wall; two thermocouples are placed along the central axis to register the longitudinal propagation (at the sample centre $50 \mathrm{~mm}$ from the left wall, and at the sample end $10 \mathrm{~mm}$ from the right wall); and one thermocouple is placed on either side of the sample to register the lateral propagation ( $10 \mathrm{~mm}$ from side walls and $30 \mathrm{~mm}$ from the igniter).

The effect of the size of the experimental apparatus is always a concern in small-scale experiments. However, smouldering propagates very slowly and thus boundary effects are felt only after long times. Thus ignition behaviour is not expected to be influenced by the size of the apparatus. To minimize the effect of the boundaries (the apparatus size) insulating board is used on the bottom and the four sides. Regarding spread rate and fire severity, the results from smallscale experiments are a good estimation of the general order of magnitude of smouldering.

A total of 25 samples of different moistures were tested. Figure 5 shows the thermocouple traces of two experiments, one of high moisture content (top) and another of low moisture content (bottom). The thermocouple traces serve to measure propagation rate, peak temperatures and thermal severity during combustion. Figure 5 shows that as power is supplied to the coil, the thermocouple near the igniter is the first one to register heating and the temperature rises until the igniter is turned off $30 \mathrm{~min}$ later. Ignition resulted in a maximum temperature at the peat in contact with the coil in the range 400 to $670{ }^{\circ} \mathrm{C}$, depending on the moisture content of the sample in the test. A failed peat ignition (Fig. 5 top) is characterized by a drop of the thermocouple readings near the igniter shortly after the ignition source is turned off ( 10 to $30 \mathrm{~min}$ afterwards) and that the maximum temperature reached away from the igniter does not exceed $100{ }^{\circ} \mathrm{C}$. A successful peat ignition is followed by sustained smouldering front (Fig. 5 bottom) and the subsequent rise of temperatures at different locations reaching typical smouldering peak temperature between 500 to $600{ }^{\circ} \mathrm{C}$. The sample in Fig. 5 is fully consumed after $3.7 \mathrm{~h}$. 
The experimental series show that samples with moisture content above $135 \%$ did not ignite. The measured mass loss for these samples was below $25 \%$, which corresponds to the lost fraction of the water and a small fraction of the organic content of the peat near the igniter. In this moisture range the maximum temperature of $400{ }^{\circ} \mathrm{C}$ was reached in the peat surrounding the igniter: The temperature of the peat elsewhere in the sample did not rise above $80{ }^{\circ} \mathrm{C}$. Figure 5 (top) shows the thermocouple traces of one of these experiments. The lack of propagation at high moisture contents is because the heat released by the burning organic content is lower than the heat required to evaporate the water of the surrounding peat and cannot preheat the biomass laying ahead of the smouldering front (Frandsen, 1987; Frandsen, 1997).
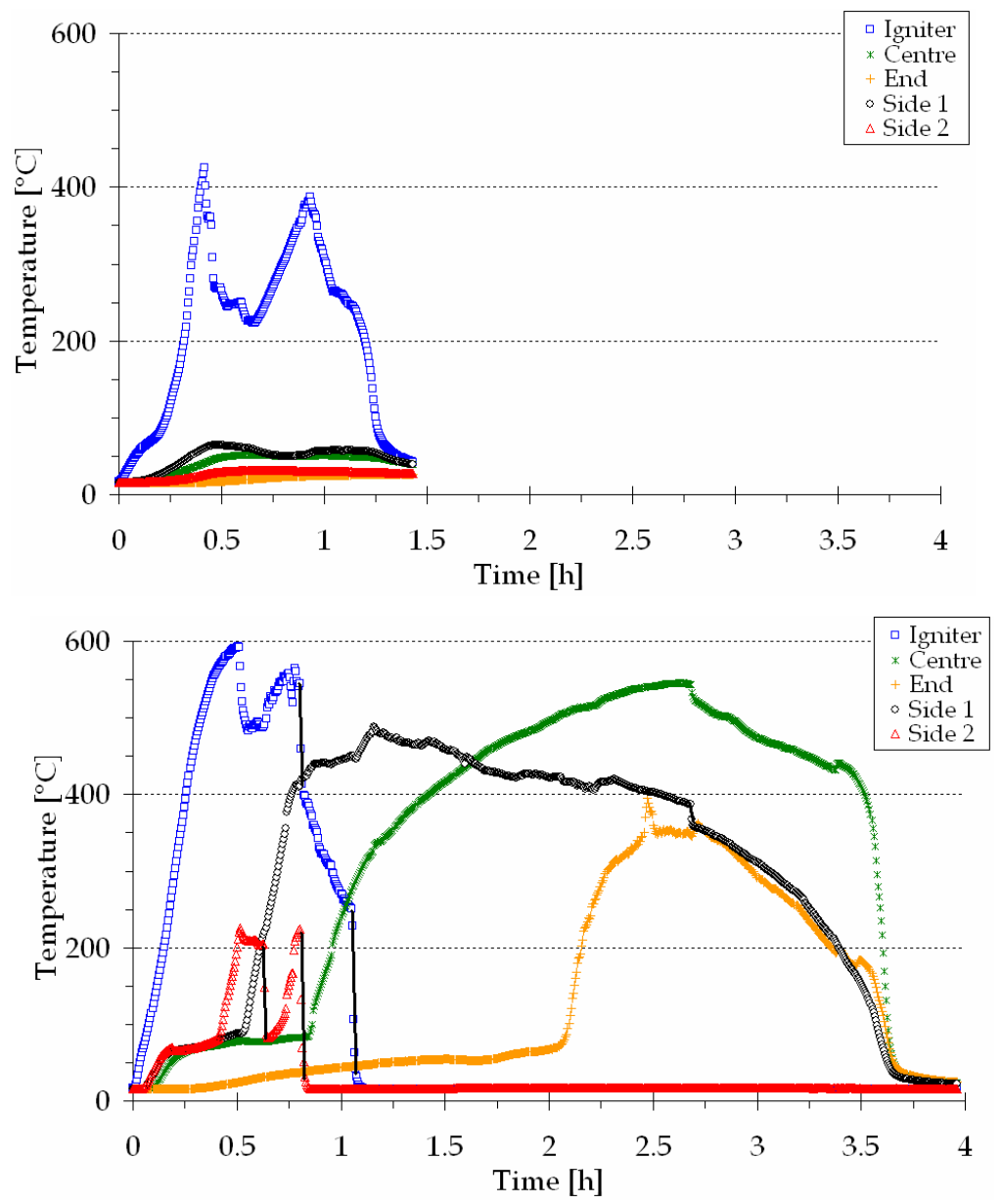

Figure 5. Thermocouple readings from two of the experiments. Top) Sample of high moisture that did not ignite (moisture content $153 \%$ ), registering a final mass loss of 9.5\%. Bottom) Sample of low moisture that underwent strong ignition and propagation (moisture content IO2 $\%$ ), registering a final mass loss of $97 \%$.

Dark continuous lines indicate the effect of the thermocouple being displaced by the collapsing soil.

Samples with moisture content between $\mathbf{1 1 5}$ and 135\% underwent local ignition but the smouldering did not selfpropagate away from the igniter area. When the ignition source was switched off the smouldering extinguished 30 min afterwards and the burning front did not propagate more than $40 \mathrm{~mm}$ away from the igniter. This is referred as weak peat ignition. The mass loss achieved was in the range 25 to $75 \%$ and corresponds to the loss of a large fraction of the water in the sample and part of organic matter in the igniter area. The maximum temperature reached was around $450^{\circ} \mathrm{C}$ near the igniter.

Samples with moisture content below 115\% underwent strong peat ignition and reached mass losses above 90\%. This mass loss corresponds to all the water and most of the organic content of the sample, leaving only the mineral content and some charred peat. The thermocouple readings from one of the strong ignition can be seen in Figure 5 (bottom). The ignition source reaches a temperature of $600{ }^{\circ} \mathrm{C}$ and then is switched off. The other thermocouple traces start to increase at subsequent times registering the propagation of the hot front. The temperature plateaus seen between 80 and $100{ }^{\circ} \mathrm{C}$ (Figure 5 bottom) correspond to the evaporation of the moisture in the peat. The time spans of these plateau is proportional to the initial moisture content. The maximum temperature reached away from the igniter area is $580{ }^{\circ} \mathrm{C}$. 
The average propagation velocity and total mass loss rate for the samples below the critical moisture were approximately $30 \mathrm{~mm} \cdot \mathrm{h}^{-1}$ and $38 \mathrm{~g} \cdot \mathrm{h}^{-1}$ respectively.

The measured mass loss vs. moisture content for all the tests is presented in Figure 6. The results show the sharp transition separating low and large mass losses at the critical moisture of $125 \pm 10 \%$. This value compares well to the work by Frandsen (1987) whose experiments showed that the critical moisture for peat moss is $105 \%$ for a mineral content of $8 \%$ in dry mass (the content of peat in our experiments).

\section{5. $\quad$ FIRE SEVERITY}

There is little experimental information in the literature on the fire severity of smouldering fires and the effects on the soil. No quantification of this severity has been found. However, analysis of the smouldering experiments presented in the previous section can be used to quantify the impact of such fires. It is proposed that fire severity on the soil is given by the thermal severity and the mass loss. The thermocouple readings allow expressing the thermal severity in terms of temperature and residence time, and the mass loss measurements allow quantifying the soil removal.

The peak temperatures observed away from the igniter for a sample that burned completely (moisture below the critical) was between 500 and $600{ }^{\circ} \mathrm{C}$ for more than $20 \mathrm{~min}$, enough to produce severe and irreversible damage to the affected soil, including its sterilization. The thermal severity has been quantified in terms of the period of time that a location is exposed to temperatures above a given threshold. The analysis is done by considering the average residence time in all the experiments of each ignition type. The results are shown in Table 1 and Figure 7. The results in Table 1 have been divided in two regions.

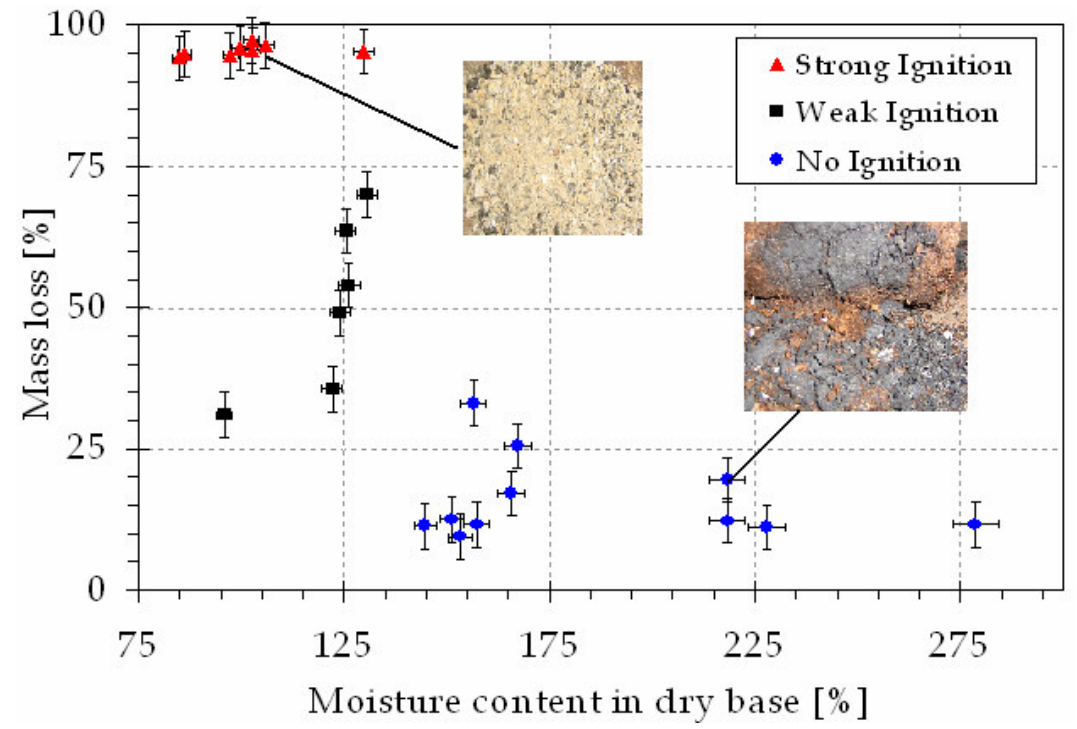

Figure 6: Results for total mass lost in the sample vs. moisture content for all 25 experiments. The results show a sharp transition separating low and large mass losses at the critical moisture of $125 \%$. The superimposed photographs show the remains of the sample after the experiment. Natural variations in the sample homogeneity produce some irregularity in the mass loss.

One region is defined as being near the igniter, where the thermal severity is controlled by the external event of the ignition protocol. The other region is the one away from the igniter and far from the boundaries (the middle of the sample) where conditions would represent those of natural smouldering fires propagating freely. A classification of three types of peat ignition has been used: no-ignition, weak ignition and strong ignition. It is proposed that the results from the strong peat ignition characterize fire the severity in the burnt soil layers. The results from the weak ignition characterize the severity at the perimeter of fire, i.e. near the demarcation line in the forest ground between a smouldered layer and a pristine one. These perimeters are typically marked by a layer of charred peat indicating significant heating but no selfpropagation and are either vertical or horizontal unburnt layers. The experimental observations for the no-ignition characterize the severity some distance away from the perimeter of the burned layers (in the order of $5 \mathrm{~cm}$ ). These results could be used by soil and forest scientists to infer the damage to the soil inside and at the perimeter of a smouldering fire.

Large differences can be seen between the residence times recorded in the regions near and away from the igniter. On average, no-ignition samples barely go above $500{ }^{\circ} \mathrm{C}$ near the igniter and do not go above $200{ }^{\circ} \mathrm{C}$ away from igniter. In the 
samples that underwent weak-ignition, some differences can be seen between the two regions but, near the igniter, thermal severity is considerably higher than in the region away from it (more than twice the resident time for each threshold). The results for the strong ignition are almost identical in both locations, indicating that the event is independent of the external ignition and that the thermal severity for smouldering fires would be well characterized by these results.

A note can be made here to guide in the interpretation of the results in Table 1 and Figure 7 . Two severe sterilization methods are used to kill microorganisms in medical apparatus (Block, 2001): steam autoclave at $121{ }^{\circ} \mathrm{C}$ for 15 to $30 \mathrm{~min}$ and the dry-heat oven at 150 to $160^{\circ} \mathrm{C}$ for $2 \mathrm{~h}$. The relationship between temperature and the inverse of time is exponential, and thus the residence time required to reach sterilization at higher temperature than these is drastically reduced from the specified values. Comparison of these sterilization methods with our results indicates that the temperature-time distribution inside the burned layers and at the fire perimeters far exceeds the threshold for sterilization.

Table I: Average residence times above a given temperature for the different smouldering regimes and regions. 'Near igniter' refers to measurements of the thermocouple placed at the ignition source and 'Far from Igniter' refers to the thermocouple farthest from the ignition source $(50 \mathrm{~mm})$

\begin{tabular}{|c|c|c|c|c|c|c|}
\hline \multirow{2}{*}{ Temperature } & \multicolumn{2}{|c|}{$\begin{array}{c}\text { No Ignition } \\
\text { [min] }\end{array}$} & \multicolumn{2}{c|}{$\begin{array}{c}\text { Weak Ignition } \\
\text { [min] }\end{array}$} & \multicolumn{2}{c|}{$\begin{array}{c}\text { Strong Ignition } \\
\text { [min] }\end{array}$} \\
\cline { 2 - 7 } & $\begin{array}{c}\text { Near } \\
\text { igniter }\end{array}$ & $\begin{array}{c}\text { Far } \\
\text { from } \\
\text { igniter }\end{array}$ & $\begin{array}{c}\text { Near } \\
\text { igniter }\end{array}$ & $\begin{array}{c}\text { Far } \\
\text { from } \\
\text { igniter }\end{array}$ & $\begin{array}{c}\text { Near } \\
\text { igniter }\end{array}$ & $\begin{array}{c}\text { Far } \\
\text { from } \\
\text { igniter }\end{array}$ \\
\hline$>100{ }^{\circ} \mathrm{C}$ & 49 & 4 & 64 & 56 & 102 & 137 \\
\hline$>200{ }^{\circ} \mathrm{C}$ & 36 & $\circ$ & 48 & 31 & 80 & 119 \\
\hline$>300{ }^{\circ} \mathrm{C}$ & 20 & 0 & 40 & 17 & 62 & 102 \\
\hline$>400{ }^{\circ} \mathrm{C}$ & 8 & 0 & 23 & 0 & 41 & 71 \\
\hline$>500{ }^{\circ} \mathrm{C}$ & 4 & $\circ$ & 3 & 0 & 13 & 24 \\
\hline
\end{tabular}

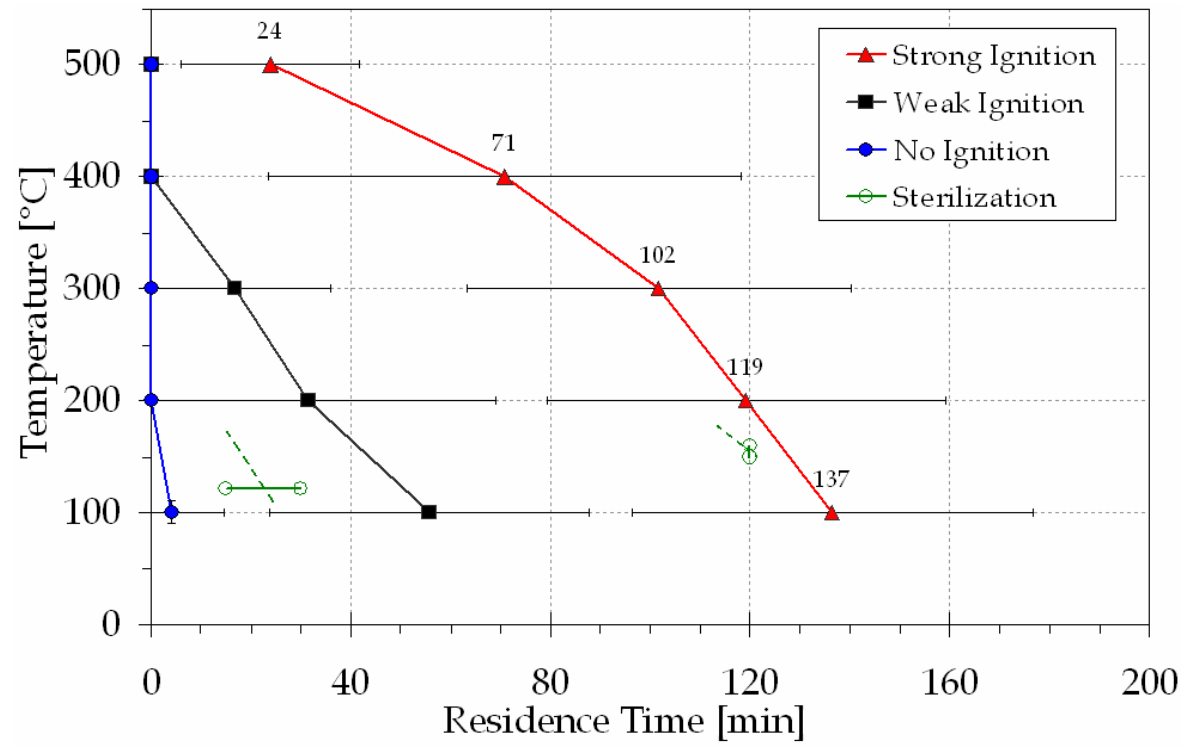

Figure 7. Thermal fire severity by smouldering measured as the average residence times above a given temperature threshold. Temperatures measured away from the igniter (i.e. thermocouple 50 mm away from it) and for the three different peat ignition regimes. Side bars indicate standard deviation. Sterilization limits via autoclave and dry heat are indicated.

Mass loss measurements shown in Figure 6 can be used to quantify the effect of smouldering on the soil in terms of mass loss. In the burned layers, the total peat mass loss is above 9०\%. Only the mineral content and a small fraction of the organic matter are left. At the edge of the burned layers (corresponding to weak ignition cases), the total peat mass loss varies significantly between 20 to $75 \%$. This suggests that here the mass loss can be anywhere in the region of a fraction of 
its water content to a significant fraction of the organic matter. The fire perimeters are typically marked by a layer of charred peat of some thickness or by a layer of mineral soil that stopped the propagation.

\section{CONCLUSIONS}

A series of smouldering experiments of boreal peat have been conducted under laboratory conditions. Peat samples of different moisture contents were exposed to an external ignition source while temperature evolution in the bed and final mass loss were measured.

The results show that moisture content governs smouldering ignition in peat. This implies that moisture distribution in shallow layers of peat would dictate if a forest site can be ignited by a surface ignition source. The depth and the area affected in case of fire will also be dictated by the moisture distribution in peat layers. The measured critical moisture content for this boreal peat is found to be $1_{25} \pm_{10} \%$ in dry base $(55 \pm 2 \%$ in wet base).

The results allow the development of a simple and conservative fire danger rating that could be used by forest managers and fire services in boreal peatlands with mineral content below $8 \%$ in dry base. If field moisture measurements indicate that the water content in shallow peat layers is below $115 \%$ in dry base, then the fire danger would be high, if between $115 \%$ and $135 \%$ the danger would be intermediate, and for moistures above $135 \%$ the fire danger would be low.

The severity of the smouldering fires has been quantified in terms of temperature and residence times using measurement from laboratory experiments. The prolonged heating rates from smouldering result in high severity. Temperatures in excess of $300{ }^{\circ} \mathrm{C}$ for residence times of $\mathbf{1} \mathrm{h}$ lead to sterilization of the soil and severe irreversible changes of physical, chemical and biological nature. In terms of peat removal, the mass loss in burnt layers is above $9 \circ \%$ while at the perimeters mass loss is between 20 and $75 \%$.

The findings of this study pertain to shallow burning fronts. The existence of deep networks of natural pipe-flow in peat (Holden and Burt 2002) and other organic soils implies than air can easily feed deep fires and that shallow fires can lead to deep fires and vice versa. Fire fronts propagating many meters deep into the subsurface need to be investigated further. Moreover, the study of smouldering fires and the response of the ecosystem will become even more important if, as climate experts predict, warmer and drier summers are to be expected in the future bringing an increased wildfire frequency.

\section{ACKNOWLEDGMENTS}

This research has been partially funded by the Met Office and Natural England and partially funded internally by the BRE Centre for Fire Safety Engineering. The authors thank the collaborations of Matt Davies, Colin Legg and Alan Gray for their comments and for providing the samples and taking the leading author to the Rothiemurchus fire. The helpful discussions with Albert Simeoni, Rory Hadden, Karl Kitchen, Jose Garcia and Juan de Dios Rivera are appreciated.

\section{REFERENCES}

- Artsybashev, E.S., Chistjakov, V.I., Gorshkov, V.V., Kuprijanov, A.I., 1983. Measures for Fires-Prevention on Peat Deposits. In: D. McClean, R. Wein (Editors), The Role of Fire in Northern Circumpolar Ecosystems, John Wiley \& Sons, Chichester, UK, pp. 259-271.

- Bertschi, I., Yokelson, R.J., Ward, D.E., Babbitt, R.E., Susott, R.A., Goode, J.G., Hao W.M., 2003. Trace gas and particle emissions from fires in large diameter and belowground biomass fuels. Journal of Geophysical Research 108 (D13), 8472.

- Block, S.S., 2000. Disinfection, Sterilization, and Preservation, Lippincott Williams \& Wilkins, Baltimore.

- Bragg, O.M., Tallis, J.H, 2001. The sensitivity of peat -covered upland landscapes. Catena 42, 345-360.

- Certini, G., 2005. Effects of fire on properties of forest solid: a review. Oecologia 143, 1-10.

- Drysdale, D., 1998. An Introduction to Fire Dynamics. 2nd Ed, John Wiley \&Sons, Chichester, UK.

- Frandsen, W.H., 1987. The influence of moisture and mineral soil on the combustion limits of smouldering forest duff. Canadian Journal of Forest Research 17 (12), 1540-1544.

- Frandsen, W.H., 1997, Ignition probability of organic soils. Canadian Journal of Forest Research 27, 1471-1477.

- Gumbricht, T., McCarthy, TS., McCarthy, J., Roy, DP., Frost, PE., Wessels, K., 2002. Remote sensing to detect subsurface peat fires and peat fire scars in the Okavango Delta, Botswana. South African Journal of Science 98, 351-360. 
- Hartford, R.A., Frandsen, W.H., 1992. When it's hot, it's hot etc. or maybe it's not! (Surface flaming may not portend extensive soil heating). International Journal of Wildland Fire 2, 139-44.

- Hille, M.G., Stephens, S.L., 2005. Mixed conifer forest duff consumption during prescribed fires: tree crown impact. Forest Science 51 (5), 417-424.

- Holden, J., Burt, T.P., 2002. Piping and pipeflow in a deep peat catchment. Catena 48, 163-199.

- Joosten, H., Clark, D., 2002. Wise Use of Mires and Peatlands. Background and Principles including a Framework for decision making. International Mire Conservation Group and International Peat Society, NHBS Ltd, Devon, UK.

- Maltby, E., Legg, C.J., Proctor, M.C.F., 199o. The Ecology of Severe Moorland Fire on the North York Moors: Effects of the 1976 Fires, and Subsequent Surface and Vegetation Development. The Journal of Ecology 78 (2), $490-518$.

- Miyanishi, K., Johnson, E.A., 2002. Process and patterns of duff consumption in the mixedwood boreal forest. Canadian Journal of Forest Research 32, 1285-1295.

- Legg, C.J., Davies, M., 2006. Report on the July 2006 Rothiemurchus fire. School of Geosciences, The University of Edinburgh, Internal report.

- $\quad$ Page, S.E., Siegert, F., Rieley, J.O., Boehm, H.D.V., Jaya, A., Limin, S., 2002. The amount of carbon released from peat and forest fires in Indonesia during 1997. Nature 420, 61-63.

- Palmer, K.N., 1957. Smoldering combustion in dusts and fibrous materials. Combustion and Flame 1, 129-154.

- Perez, B., Moreno, J.M., 1998. Methods for quantifying fire severity in shrubland-fires. Plant Ecology 139, 91-101.

- Pitkänen, A., Turunen, J., Tolonen, K., 1999. The role of fire in the carbon dynamics of a mire, eastern Finland. The Holocene 9 (4), 453-462.

- Poncet, S., 2004. Green Island: Seal Colony Threatened by Fire, Falkland Islands News Network 4, Feb, http://www.smarta.com.

- Rein, G., Cohen, S., Simeoni, A., 2008. Carbon emissions from smouldering peat in shallow and strong fronts. Proceedings of the Combustion Institute 32, 2008 (in press).

- Santa Barbara County, 2000. Fire in Peat Bog, On the air - Air Quality News 58, Oct, http://www.sbcapcd.org.

- Smith, S.M., Newman, S., Garrett, P.B., Leeds, J.A., 2001. Differential effects of surface and peat fire on soil constituents in a degraded wetland of the northern Florida Everglades. Journal of Environmental Quality 30, 19982005 .

- $\quad$ Stephens, S.L., Finney, M.A., 2002. Prescribed fire mortality of Sierra Nevada mixed conifer tree species: effects of crown damage and forest floor combustion. Forest Ecology and Management 161, 261-271.

- Svensen, H., Dysthe, D.K., Bandlien, E.H., Sacko, S., Coulibaly, H., Planke, S., 2003. Geology 31, 581-584.

- Usup, A., Hashimoto, Y., Takahashi, H., Hayasaka, H., 2004. Combustion and thermal characteristics of peat fire in tropical peatland in Central Kalimantan, Indonesia. Tropics 14 (1), 1-19.

G. Rein, N. Cleaver, C. Ashton, P. Pironi, JL. Torero, "The Severity of Smouldering Peat Fires and Damage to the Forest Soil", Catena 74 (3), pp. 304-309, 2008. 